\title{
Synthesis and characterization of HDA/NaMMT organoclay
}

\author{
C YÜRÜDÜ, S İşÇI, C ÜNLÜं, O ATICI \\ Department of Physics, 'Department of Chemistry, ${ }^{\star}$ Department of Geology, Istanbul Technical University, 34469, \\ Maslak, Istanbul, Turkey
}

MS received 4 May 2005; revised 1 August 2005

\begin{abstract}
In this study, the rheologic and colloidal characterizations of sodium montmorillonite (NaMMT) were examined. Hexadecylamine $\left(\mathrm{CH}_{3}\left(\mathrm{CH}_{2}\right)_{15} \mathrm{NH}_{2}, \mathrm{HDA}\right)$ was added to the bentonite water dispersion $(2 \%, \mathrm{w} / \mathrm{w})$ in different concentrations in the range $5.6 \times 10^{-4}-9.4 \times 10^{-3} \mathrm{~m} \mathrm{~mol} / \mathrm{l}$. The rheological and electrokinetic behaviour of aqueous montmorillonite dispersions was investigated as a function of solid content and HDA concentration. The basal spacings of the HDA/NaMMT composites were studied by X-ray diffraction. The FTIR spectra were obtained from the modified bentonite products, which revealed the characteristic absorbances after treatment with HDA.
\end{abstract}

Keywords. Montmorillonite; hexadecylamine; organoclay.

\section{Introduction}

Clays are widely used in industrial products and processes. The use of clay suspensions is important in ceramic industry as well as in the production of paper, detergent, and paints; foundry, civil engineering; and in drilling operations. The determination of the rheological characteristics such as viscosity and thixotropy of the claywater dispersions is of great importance for the ceramic industry.

Bentonite, which is a kind of smectite group clay mineral, is almost made up of $80 \%$ of montmorillonite and contains a crystal lattice with three layers. It has a variety of uses because of its colloidal property. When it is mixed with water, it swells significantly. In water and in some organo environments, it produces a smooth homogenous slurry having high plasticity. Layered smectite-type montmorillonites possess a negative surface charge which is compensated by exchange of cations, such as $\mathrm{Na}^{+}$or $\mathrm{Ca}^{2+}$. Bentonite dispersions are sensitive to the exchangeable cations and $\mathrm{pH}$. The valency of the exchangeable cations, monovalent or divalent, has a strong influence on the flow properties (Espinasse and Siffert 1979; Lagaly 1989; Angle and Hamza 1989; Permien and Lagaly 1994; Güngör 1998; Günister et al 2004). As organic cations exchange for exchangeable ions on the mineral surfaces, the cations are released into solution. The organic cations may also enter into ion-exchange reactions with exchangeable cations between the layers (Espinasse and Siffert 1979; Angle and Hamza 1989; Lagaly 1989; Alemdar et al 2005). The surface of the clay may be modified to make

*Author for correspondence (nurfer@itu.edu.tr) it strongly organophilic. Recently, nanoscale composites of polymers with organo-clay have been studied extensively. Montmorillonite is the most widely used layered silicate in polymer nanocomposite studies (Sheng et al 1996; Pan et al 1997; Chen et al 1998; Chang et al 2001, 2002; Chang and An 2002; Chen and Curliss 2003).

In this study, the Turkish natural bentonite sample has been identified as Ca-montmorillonite (CaMMT). The Na-activated montmorillonite (NaMMT) was obtained from natural montmorillonite by treating the clay with $\mathrm{NaCl}$ solution. The effect of HDA on the rheological properties and colloidal nature of the NaMMT dispersion is investigated. Besides, measurement of the colloidal and rheological properties, the NaMMT and HDA/NaMMT dispersions have been examined in detail with XRD and FTIR analysis.

\section{Experimental}

The clay sample was obtained from the bentonite deposits in Bigadiç-Balíkesir, Turkey (courtesy of Unikim Ltd.). Ore samples have been identified as Ca-montmorillonite clay minerals using X-ray diffractometer (Philips model PW 1140, Holland), indicating dioctahedral structure of montmorillonite with minor amount of illite, quartz and feldspar. Natural montmorillonite is labeled as CaMMT and Na-activated clay as NaMMT.

The flow behaviour of the dispersions was measured in a Brookfield DVIII + type low-shear rheometer. The sample was dispersed in water $(2 \% \mathrm{w} / \mathrm{w})$ and shaken overnight. An adsorption time of $24 \mathrm{~h}$ was adopted for the surfactant. The rheological behaviour of the clay suspensions was obtained by shear stress-shear rate mea- 
surements within $0-350 \mathrm{~s}^{-1}$ shear rates. Rheological measurements were carried out in duplicate.

The zeta potential measurements were carried out using a zetasizer equipment (Malvern Instruments, Zetasizer 2000, UK). The optical unit of the zetasizer 2000 contains a $5 \mathrm{~mW} \mathrm{He}-\mathrm{Ne}(638 \mathrm{~nm})$ laser. Before the measurements, all the dispersions were centrifuged at $4500 \mathrm{rpm}$ for $30 \mathrm{~min}$. Supernatants were then used for zeta potential measurements. To make an electrophoretic mobility measurement in this instrument, laser beams were crossed at a particular point in the cell. Particles in the cell were illuminated by these beams. At the crossing point of the beams, Young's interference fringes formed. Particles moving through the fringes under the influence of the applied electric field scatter light whose intensity fluctuates with a frequency that is related to the particle velocity. The photons detected by the photomultiplier are fed to a digital correlator, the resulting function being analysed to determine the frequency spectrum, from which the mobility and hence the zeta potential are calculated. Measured electrophoretic mobilities were converted to zeta potential using established theories. Zeta potential was measured by injecting a small portion of the supernatant into the cell of the Zetasizer 2000 instrument at room temperature.

The obtained film samples of intercalated clay with different HDA concentrations were analysed by X-ray diffraction. X-ray diffraction (XRD) measurements were performed at room temperature using $\mathrm{Ni}$-filtered $\mathrm{Cu}-\mathrm{K} \alpha$ radiation. Infrared analyses $\left(400-4000 \mathrm{~cm}^{-1}\right)$ were performed on a FTIR spectrophotometer (Jasco Model FT/IR5300, Japan) using $\mathrm{KBr}$ pellets with a concentration of $1 \%$. Spectral outputs were recorded either in absorbance or in transmittance mode as a function of wave number. Hexa- decylamine $\left(\mathrm{CH}_{3}\left(\mathrm{CH}_{2}\right)_{15} \quad \mathrm{NH}_{2}, \mathrm{M}_{\mathrm{W}}=241.46\right)$ was purchased from Aldrich Chemical Co., USA and used as received.

\section{Results}

Figure 1 shows typical shear rate $(\dot{\gamma})$-shear stress $(\tau)$ curve for a $2 \%$ w/w $\mathrm{Ca}$ and Na-montmorillonite dispersions. The dispersions of the CaMMT exhibit nearly Newtonian behaviour. The viscosity of a Newtonian dispersion is the shear stress versus shear rate ratio. Yield value was not found and because of this we infer that the interaction between the particles of $2 \%$ dispersions is very small. The dispersions of NaMMT exhibit Bingham plastic flow behaviour. The apparent viscosity values at $55 \mathrm{~s}^{-1}$ of CaMMT and NaMMT have been found to be 1.25 and $15.27 \mathrm{mPas}$, respectively. This difference is caused by the change in swelling and dispersion behaviour of the neutral bentonite after the activation process. Exchangeable cations, which determine orientation of many physical properties of bentonitic clays such as particle size, surface charge, surface area, particle number per unit volume etc also have a strong influence on the dispersion mechanisms. The increase of viscosity and consistency of CaMMT dispersions after addition of sodium ion is a direct consequence of the opposite effect of $\mathrm{Na}^{+}$and $\mathrm{Ca}^{++}$ions. When clays are dispersed in water, NaMMT has unique crystal layer in very fine colloidal particles with sizes ranging from 10-100 $\mu \mathrm{ms}$, because the electrostatic attraction among the crystal layers is weak. On the other hand, for the CaMMT, the mean particle size is kept at several $\mu \mathrm{m}$ 's in water, because the electrostatic attraction among the crystal layers is strong.

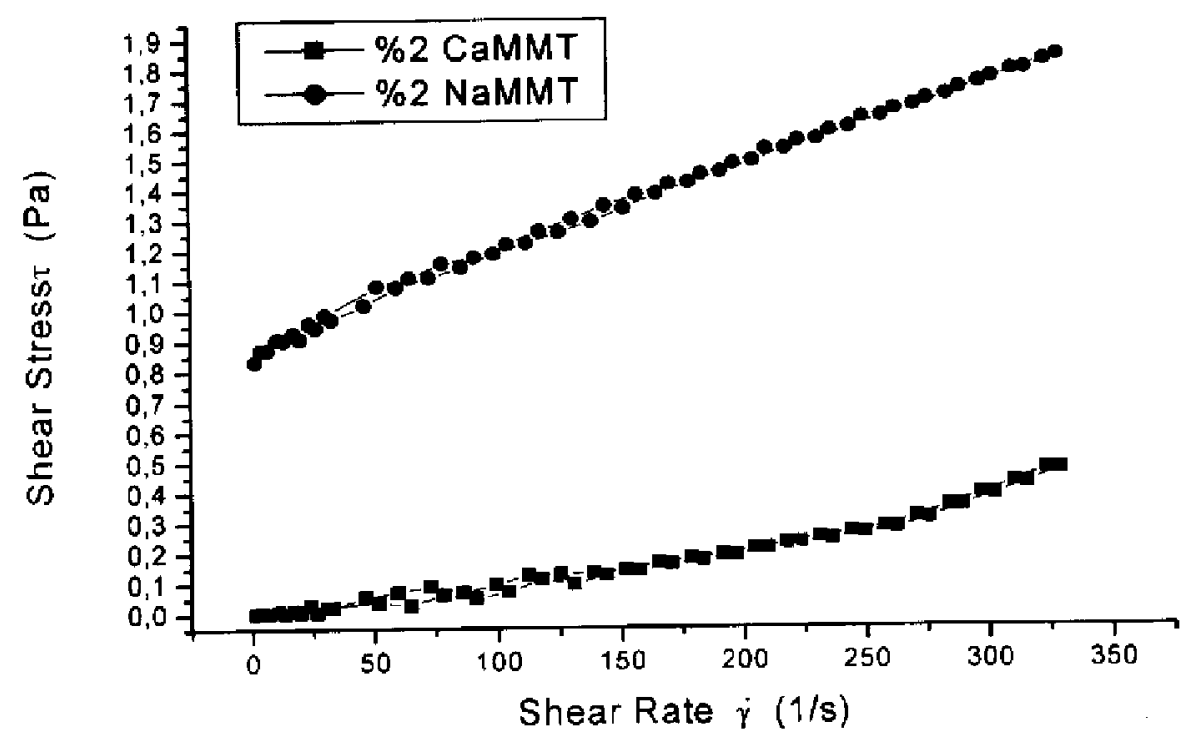

Figure 1. The shear stress-shear rate rheogram for CaMMT and NaMMT dispersions. 
Rheological parameters are sensitive to solid content. By increasing the solid content of the dispersions, the viscosity and yield values increase. The flow and appearing viscosity-shear velocity curves of the 1, 2, 3, 4, 5 and $6 \%$ clay dispersions that have been prepared with the NaMMT sample, have been drawn and the flow models determined. The shear stress versus shear rate for suspensions containing different concentrations of NaMMT samples are shown in figure 2 . The dispersions (1, 2 and $3 \%$ w/w) of NaMMT exhibited Bingham plastic behaviour. The yield values have been increased by the solid ratio. The increase in the yield value with clay concentration (solid content) is due to the increase of number of clay particles in the dispersion (figures $2 \mathrm{a}$ and $\mathrm{b}$ ). The Bingham yield value (extrapolated shear stress) is a criterion of particle-particle interaction and a better parameter for quantifying the structure of a flocculated system.

Hexadecylamine was used as an organophilic alkylamine in organo-clay. In figure 3 , the yield value of bentonite dispersions was plotted as a function of increasing HDA concentrations. After the first addition of surfactant, the yield value of NaMMT dispersions increased. The flocculation of NaMMT dispersion was greatly in-

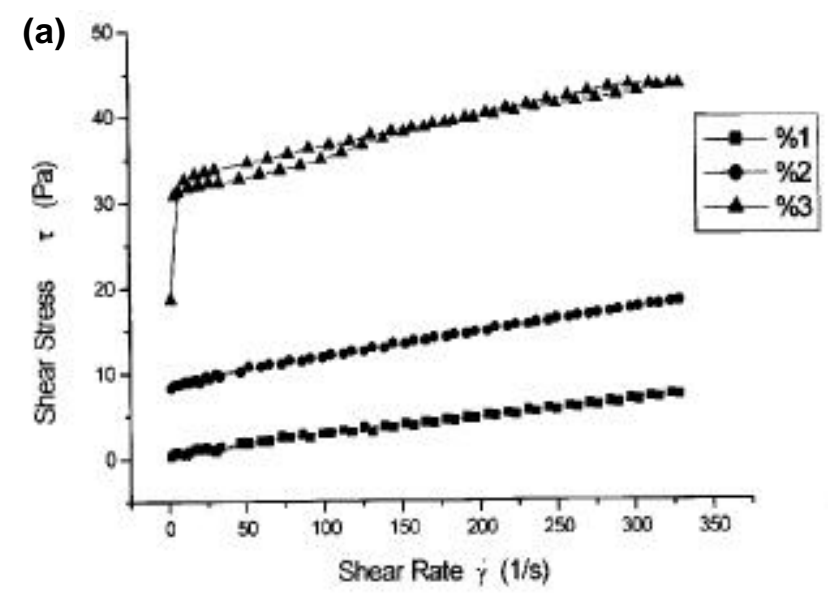

(b)

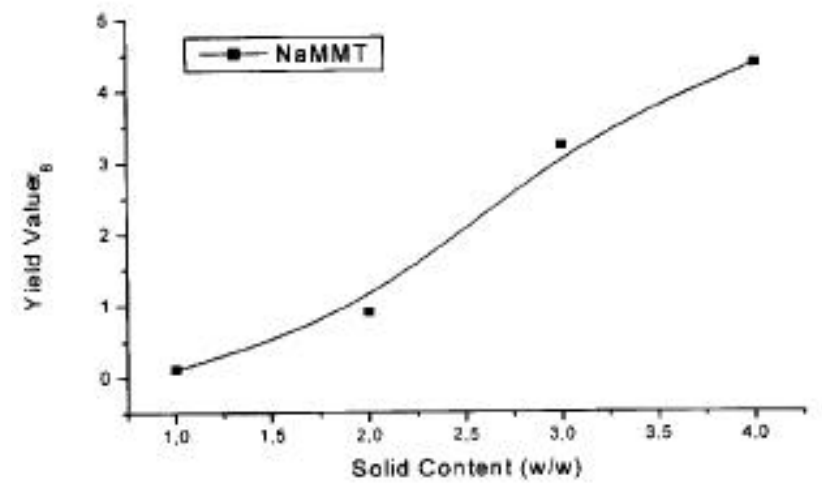

Figure 2. Effect of clay concentration (w/w) on (a) the flow curves and (b) yield value. creased by small additions of HDA and a maximum was reached at $1.87 \times 10^{-3} \mathrm{~mol} / 1 \mathrm{HDA}$. Further addition of surfactant results in a decrease in the rheological parameters and the system begins to get deflocculated.

The degree of thixotropic or antithixotropic behaviour was measured by the area of the hysteresis loop (figure 4). The area of the hysteresis loop of the flow curves, which is a measure of the degree of hysteresis, is accepted to be positive if the behaviour of the system is thixotropic, and negative if the behaviour is antithixotropic. The results indicate a gradual increase in gelation with the first addition of HDA, which reaches a maximum at $9.35 \times 10^{-4} \mathrm{~mol} / \mathrm{l}$ surfactant. After that point a decrease is observed. Further addition of HDA results in an increase in the area of the hysteresis loop.

In figure 5 , the flow curves of $2 \mathrm{wt} . \%$ bentonite dispersion and the modified organo-clay with $5.91 \times 10^{-4}$,

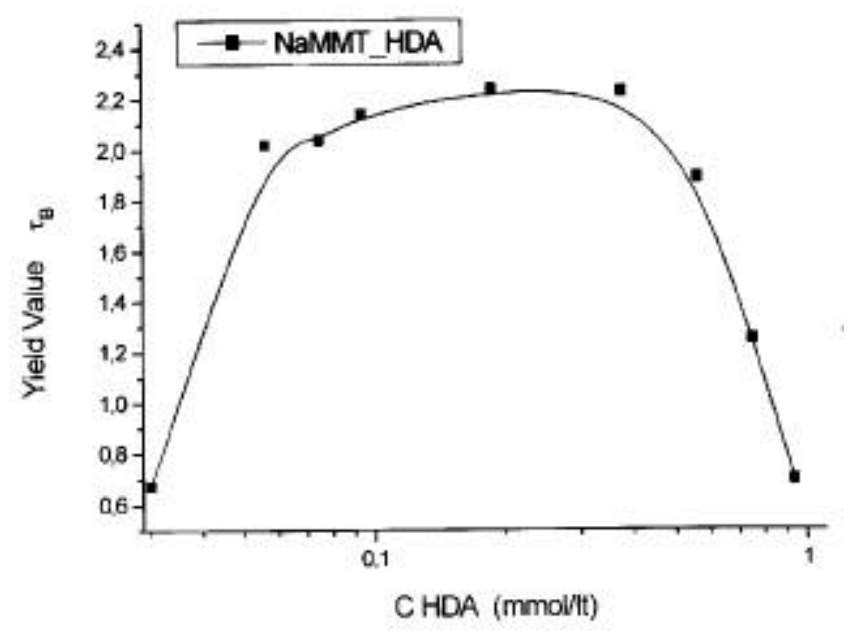

Figure 3. The changes of the yield value of NaMMT dispersions with HDA surfactant additions.

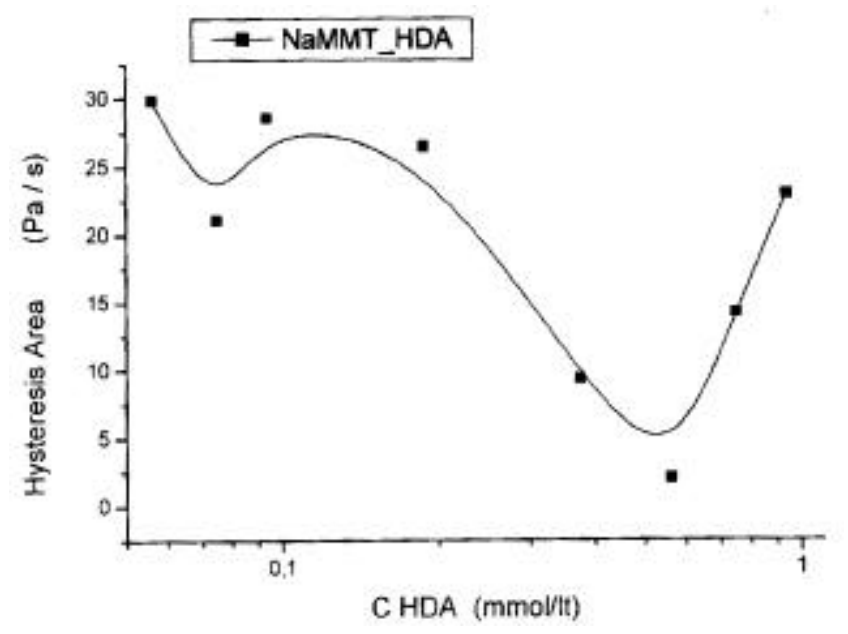

Figure 4. The hysteresis loop area of $2 \% \mathrm{w} / \mathrm{w}$ bentonite dispersion as a function of HDA concentration. 
$1.87 \times 10^{-3}, 5.61 \times 10^{-3}$ and $9.35 \times 10^{-3} \mathrm{mmol} / \mathrm{l} \mathrm{HDA}$, respectively are displayed. Figure 5 shows an increase in gelation till the $1.87 \times 10^{-3} \mathrm{~mol} / \mathrm{l}$ surfactant addition. However, at $5.6 \times 10^{-3} \mathrm{~mol} / \mathrm{l}$ surfactant addition a clear decrease is observed. This curve agrees with the curves in figures 4 and 5 since the maximum yield value (figure 5) are seen at around $1.87 \times 10^{-3} \mathrm{~mol} / \mathrm{l}$ surfactant addition. This point shows the maximum flocculation; on further addition, the system begins to get deflocculated.

Figure 6 shows the change in zeta potential with HDA concentration for NaMMT dispersions. The zeta potential is an electrical potential in the double layer at the interface between a particle, which moves in an electric field, and surrounding liquid. The surface charge property can be characterized by zeta potential and the stability of a clay solution can be measured depending on its value. Increasing of zeta potential values after the first addition of HDA clearly shows an increase in electrostatic repulsion

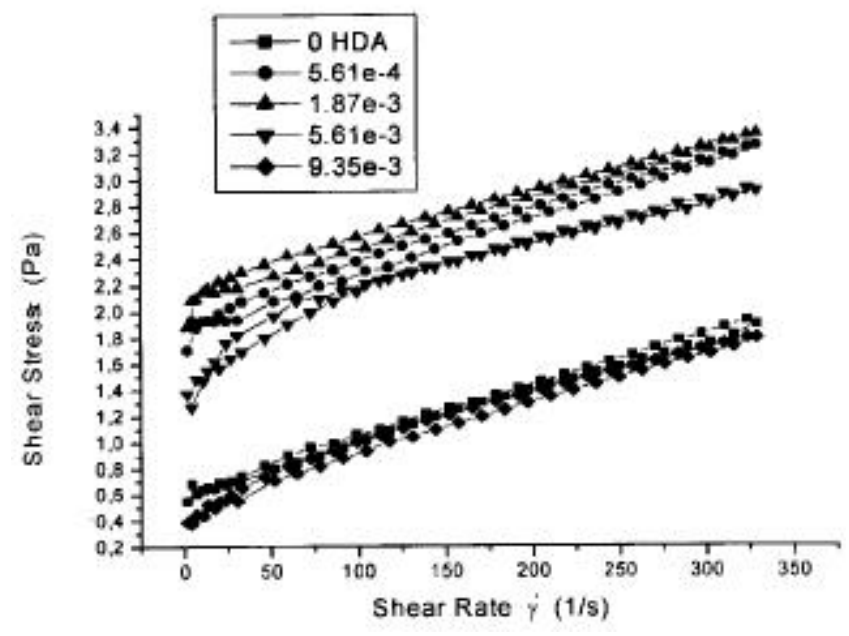

Figure 5. The changes of flow curves of NaMMT dispersions with HDA additions.

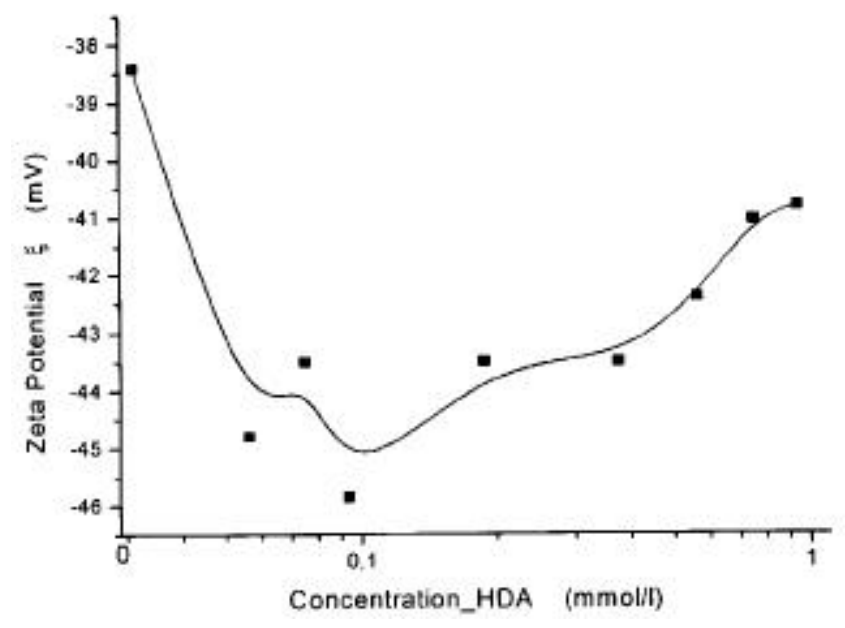

Figure 6. The changes of the zeta potential of NaLB dispersions with HDA surfactant additions. power between clay particles. However, two possible hypotheses can be proposed to explain the reason for increase in zeta potential. (i) Currently existing clusters between clay particles could be dispersed after the addition of HDA. Consequently, the system contains both large size clusters holding a number of particles together with much smaller clusters/particle sizes and therefore, electrostatic repulsion power and zeta potential will increase and (ii) positively charged edges of clay particles can make bonds with one of unbounded electrons of HDAs. Under these circumstances, electrostatic repulsion power will increase, because net charges of clay particles will be more negative. When the additive contents increase, it is possible to understand from the decrease in negative charges that some quantities of clays get

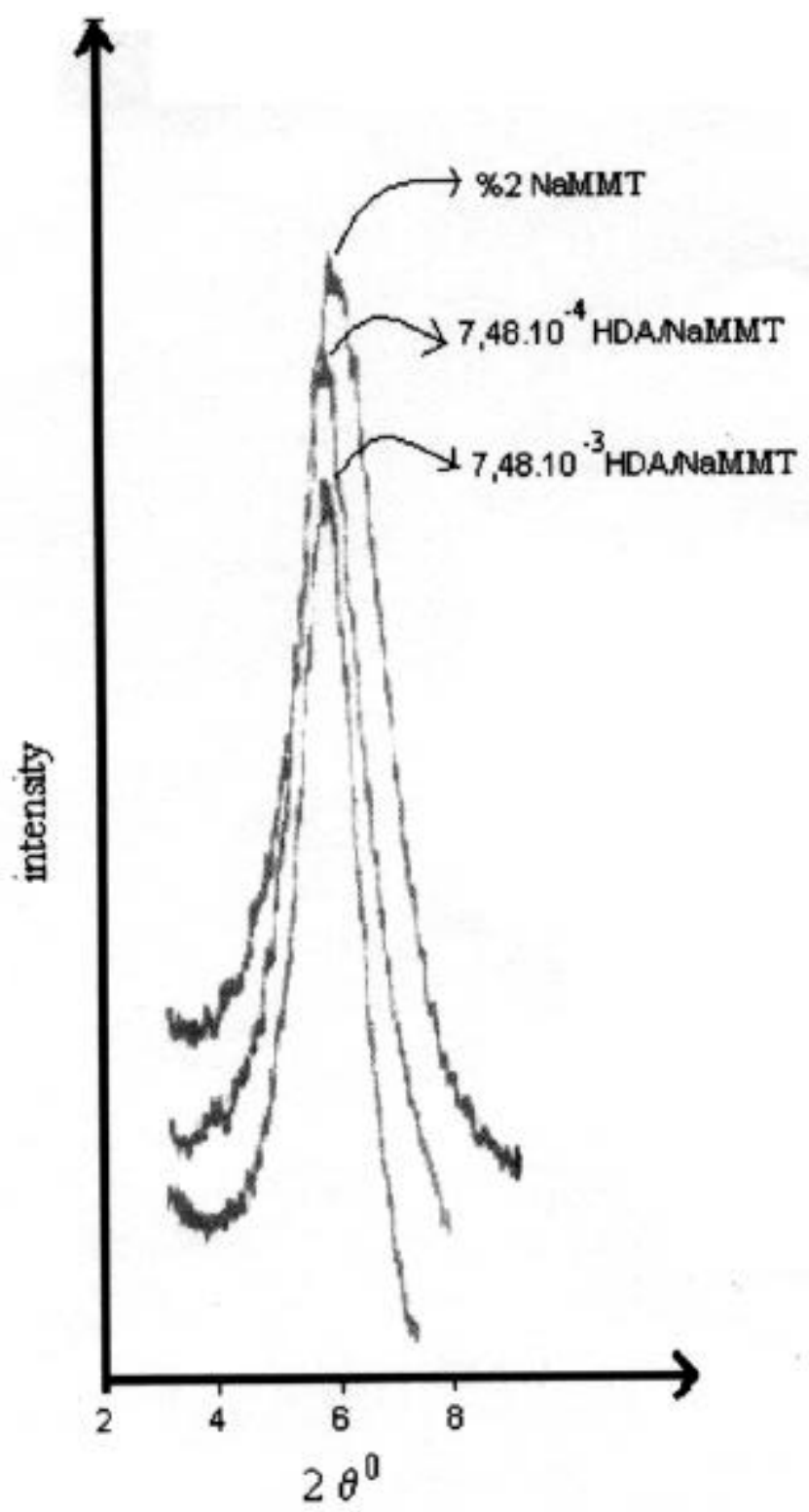

Figure 7. XRD patterns of NaLB and HDA/NaLB. 
attached on the surfaces of HDAs. However, surfactant does not cover completely the surface of clay minerals in the concentration range of this study. Dispersion shows lower thixotropic properties (figure 4) wherein zeta potentials have more negative values (figure 6). Even there is an increase in thixotropic values after last two additions of surfactants, but it never reaches the previous values of the system without surfactants. These observations are comparable with the idea of relationship between additional surfactants and deflocculation of the system (figures 3 and 5).

The clay sheets are bound with in-plane covalent bonds and therefore, their crystal structure is stable, but clay layers are held loosely with Van der Waals bonds and therefore, expansion of interlayers is commonly seen when water or organic molecules are introduced between the layers. Figure 7 shows the XRD patterns of NaMMT samples without organic modification and modified with HDA.

Figures $8 \mathrm{a}, \mathrm{b}$ and 9 compare the FTIR spectra of hexadecylamine-montmorillonite, which were prepared using solution intercalation (HDA/NaMMT), with those of activated Balíkesir montmorillonite (NaMMT) and hexadecylamine (HDA). After $\mathrm{NaHCO}_{3}$ activation, the peak corresponding to structural hydroxyl stretching at $3628 \mathrm{~cm}^{-1}$ is attributed to montmorillonite (figure $8 \mathrm{a}$ ). The broad peak centred on $3464 \mathrm{~cm}^{-1}$ is assigned to $\mathrm{O}-\mathrm{H}$ stretching.
$\mathrm{HOH}$ deformation peak centred at $1642 \mathrm{~cm}^{-1}$ is also present in the FTIR spectrum of Na-montmorillonite (figure $8 \mathrm{~b})$. The absorption bands at 1032, 797, 619, 519 and $467 \mathrm{~cm}^{-1}$ belong to $\mathrm{Si}-\mathrm{O}-\mathrm{Si}, \mathrm{Mg}-\mathrm{Al}-\mathrm{OH}, \mathrm{Al}-\mathrm{O}, \mathrm{Si}-\mathrm{O}-$ $\mathrm{Mg}$ and $\mathrm{Si}-\mathrm{O}-\mathrm{Fe}$ vibrations, respectively (figure 9). The spectrum of Na-montmorillonite that adsorbed $8 \mathrm{~g} / \mathrm{l}$ cationic surfactant HDA contains characteristic bands of all components (figures 8 and 9). Primary amine $\mathrm{NH}_{3}^{+}$asymmetrical and symmetrical stretching vibrations at 3123 and $3098 \mathrm{~cm}^{-1}$, aliphatic $\mathrm{C}-\mathrm{H}$ asymmetrical and symmetrical stretching vibrations at 2924 and $2853 \mathrm{~cm}^{-1}, \mathrm{C}-\mathrm{H}$ bendings at 1470 , and $720 \mathrm{~cm}^{-1}{ }^{+} \mathrm{NH}_{3}$ asymmetrical and symmetrical bendings at $1541-1566 \mathrm{~cm}^{-1}$ are assigned to the vibration modes of HDA. Absorbances due to structural $\mathrm{O}-\mathrm{H}$ stretching around $3621 \mathrm{~cm}^{-1}$ and $\mathrm{Si}-\mathrm{O}$ bendings at 519 and $465 \mathrm{~cm}^{-1}$ confirm the presence of $\mathrm{Na}$ montmorillonite in the dispersion. In the bentonite HDA adsorption products, the $\mathrm{O}-\mathrm{H}$ stretching peak was broadened and gave a maximum at $3428 \mathrm{~cm}^{-1}$ (figure 8 ). The bonding of HDA also results in the weakening of $\mathrm{H}-\mathrm{O}-\mathrm{H}$ stretching vibration band, which can be explained by the replacement of metal ions by HDA via ion exchange. The $\mathrm{Si}-\mathrm{O}$ stretching peak was also broadened and gave a maximum at $1030 \mathrm{~cm}^{-1}$. Absorption bands of $\mathrm{Mg}-\mathrm{Al}-\mathrm{OH}$ vibration for HDA/NaMMT $801 \mathrm{~cm}^{-1}$ are different than those for the NaMMT (figure 9). This is attributed to the relaxation of hydrogen bonding between $\mathrm{Mg}-\mathrm{Al}-\mathrm{OH}$ as

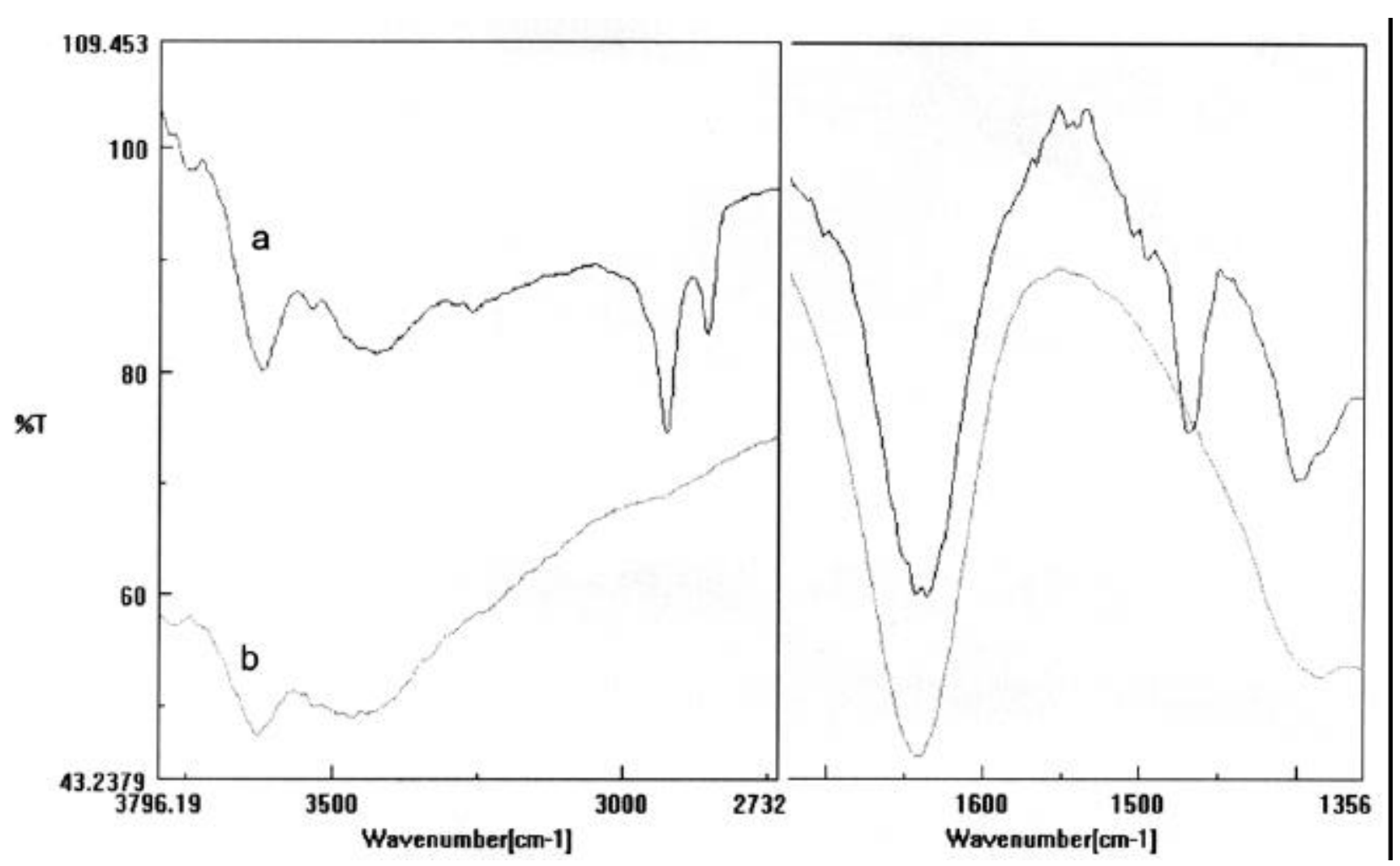

Figure 8. FTIR spectra in the $2700-3800 \mathrm{~cm}^{-1}$ and $1350-1750 \mathrm{~cm}^{-1}$ regions. (a. Na-montmorillonite and b. $8 \mathrm{mmol} / 1 \mathrm{HDA}$ adsorbed on Na-montmorillonite). 


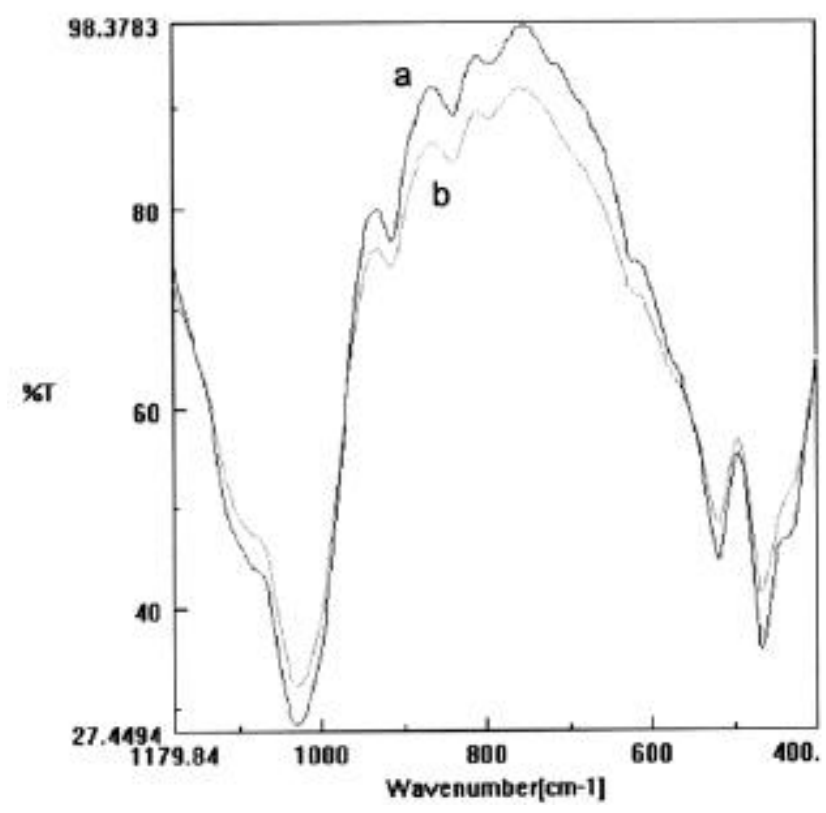

Figure 9. FTIR spectra in the $400-1180 \mathrm{~cm}^{-1}$ region (a. Namontmorillonite and b. $8 \mathrm{mmol} / \mathrm{l} \mathrm{HDA}$ adsorbed on Namontmorillonite).

well as to the hydrated water of exchangeable cationic metal ions on the montmorillonite surface, further supporting the presence of HDA.

\section{Conclusions}

The adsorbed HDA affects the rheological and electrokinetic properties of NaMMT dispersions. The degree of interaction between HDA and the bentonite particles depends on the HDA concentration in the suspension. Addition of the surfactant results in firstly the floccullant and then defloccullant effect on $2 \%$ w/w of clay dispersion.
The zeta potential measurements indicate that the HDA molecules hold onto the clay particle surfaces very weakly. XRD analyses results indicate that organic molecules did not enter sufficiently into the layers of clay structures. The comparison of FTIR spectra of the natural and HDA adsorbed montmorillonite has indicated that sorbed HDA molecules on montmorillonite are coordinated to exchangeable cations directly or indirectly through water bridges.

\section{Acknowledgement}

This research project is supported by the Istanbul Technical University, Research Fund (Project No: 30451).

\section{References}

Alemdar A, Güngör N, Ece O I and Atící O 2005 J. Mater. Sci. 40171

Angle C W and Hamza H A 1989 Appl. Clay Sci. 4263

Chang J H and An Y U 2002 J. Polymer Sci.: Part B 40670

Chang J H, Park D K and Kyo J In 2001 J. Polymer Sci.: Part B 39471

Chang J H, Park D K and Ihn K J 2002 J. Appl. Polym. Sci. 84 2294

Chang J H, Uk Y, An G and Sur S 2003 J. Polym. Sci. 4194

Chen C and Curliss D 2003 Nanotechnology 14643

Chen G, Han B and Yan H 1998 J. Colloid Interface Sci. 158201

Espinasse P and Siffert B 1979 Clays and Clay Miner. 279284

Güngör N 1998 Revue Roumaine de Chimie 43121

Günister E, İsçi S, Alemdar A and Güngör N 2004 Bull. Mater. Sci. 27317

Lagaly G 1989 Appl. Clay Sci. 4105

Pan J, Yang G, Han B and Yan H 1997 J. Colloid. Interface Sci. 194276

Permien T and Lagaly G 1994 Clay Miner. 29751

Sheng G, Xu S and Boyd S A 1996 Wat. Res. 301483 